\title{
LA POESÍA ESPAÑOLA DE POSGUERRA A LA LUZ DE LA HERMENÉUTICA CONTEMPORÁNEA. TRES CATAS CRÍTICAS
}

\author{
THE SPANISH POST-WAR POETRY AND \\ THE CONTEMPORARY HERMENEUTICS. \\ THREE TASTING REVIEWS
}

\author{
Antonio Rivero Machina \\ Universidad de Extremadura
}

Resumen: En este trabajo observaremos, desde un análisis de su recepción histórica, las distintas interpretaciones críticas que ha ido conociendo el ámbito poético español de la posguerra desde su contemporaneidad hasta nuestros días. Centraremos nuestra atención en tres estadios de recepción significativos con unas tres décadas de diferencia entre sí: el análisis estilístico realizado por Dámaso Alonso a mediados del siglo xx, la construcción sociológica de José-Carlos Mainer en los años de la llamada Transición democrática y la lectura de la poesía de posguerra como polisistema realizada por Joaquim Espinós a principios del siglo Xxi. Con ello, se pretende observar el devenir de una recepción crítica con más de seis décadas de vida que ha ido evolucionando al tiempo que lo hacían tanto las corrientes hermenéuticas imperantes como la propia historia política del país.

Palabras Clave: poesía; posguerra; estilística; sociocrítica; polisistemas.

AвSTRACT: The purpose of this research is to systematically analyze the different critical constructions that the post-Spanish Civil War poetry has experienced from that period until today. For that purpose, we focus our attention on three significant stages: Dámaso Alonso's stylistic analysis in the fifties, José-Carlos Mainer's sociological construction in the Democratic Transition years, and the reading of the Spanish post-Civil War poetry as a polisystem made by Joaquim Espinós in the early years of the twenty-first century.

KeY-Words: Spanish poetry; Spanish post-War; Stylistics; Sociocriticism; Polysystem Theory. 
Si sometemos a debate determinadas «construcciones críticas» en torno a la poesía española de posguerra, más o menos consolidadas, frente a una siempre más compleja «realidad histórica», se nos revelará en sí misma toda una historia de su recepción crítica $^{1}$. No en vano, fue tan solo cuatro años después del discurso en que Antonio Rodríguez-Moñino opuso ambos sintagmas cuando Hans Robert Jauss pronunció su lección inaugural como catedrático en la Universidad de Constanza, dando a luz a la llamada «Estética de la recepción» que él mismo encabezaría ${ }^{2}$. En ella, el profesor alemán marcaba las líneas maestras de una corriente teórica que tendrá en él y su concepto de la «Recepción histórica»-Rezeptionsästhetik-, así como en su colega de universidad Wolfgang Iser y su «lector implícito» de la «Estética del efecto» —Wirkungsästhetik-, sus principales pilares ${ }^{3}$. Recogían Iser y Jauss hallazgos hermenéuticos de Heidegger y Roman Ingarden, así como de la fenomenología de Husserl y también de los estructuralistas checos Jan Mukařovský y Felix Vodička, en un debate que tuvo en los años sesenta su maduración y en los setenta su periodo de mayor influencia (Viñas Piquer, 2007: 494-498).

En las ya citadas tesis de Jauss, formuladas definitivamente en La historia de la literatura como provocación a la crítica literaria, de 1967, quedaban sistemáticamente fijados los principios que regirán la noción vigente de «Recepción histórica» o Rezeptionsästhetik:

1 Evocamos, claro está,la célebre conferencia de Rodríguez-Moñino «Construcción crítica y realidad histórica en la poesía española de los siglos XVI y XVII», escrita en julio de 1963. Una edición reciente del texto se encuentra en RodríguezMoñino (2012).

2 El título de la conocida alocución de 1967, parafraseando a Schiller, fue «¿Qué es y para qué propósito se estudia la historia literaria?». Tres años después el profesor alemán retocaba y ampliaba sus conclusiones en Literaturgeschichte als Provokation der Literaturwissenschaft (Constanza, Universitätsverlag Konstanz, 1967). La primera edición española fue publicada en La literatura como provocación (Barcelona, Península, 1976).

3 Para un acercamiento a algunos de los principales textos teóricos de la también llamada «Escuela de Constanza», puede consultarse Mayoral (1987). 
Una renovación de la historia de la literatura requiere eliminar los prejuicios del objetivismo histórico y fundamentar la estética tradicional de la producción y de la presentación en una estética de la recepción y los efectos. La historicidad de la literatura no se basa en una relación de «hechos literarios» establecida post festum, sino en la previa experiencia de la obra literaria por sus lectores. Esta relación dialógica es también el primer hecho primario para la historia de la literatura, pues el historiador de la literatura debe convertirse siempre en lector antes de comprender y clasificar una obra; dicho de otro modo: antes de poder fundamentar su propio juicio en la conciencia de su posición actual en la serie histórica de lectores (Jauss, 2000: 160).

Declarándonos así, siguiendo a Jauss, «lectores históricos» de una poesía de posguerra que recibimos desde nuestra contemporaneidad, aceptamos con ello heredar y asumir una serie de lecturas - desarrolladas, primero, bajo un régimen dictatorial o desde su exilio; después, bajo una joven democracia, en construcción y afirmación, y, más tarde, en consolidación y cuestionamiento- condicionadas por un «horizonte de recepción» marcado tanto por lo literario como por lo extraliterario. Asumir esta distancia que nos separa ya del cronotopo estudiado a la luz de nuestro presente implica conocer mejor todas aquellas lecturas críticas que han mediatizado el camino que ahora hemos de recorrer hasta aquellos días. Ahora bien, si en ocasiones es la falta de una cantidad verdaderamente significativa de datos y testimonios lo que dificulta la óptima "construcción crítica» del estudioso - y no es tal nuestro caso, dado que el corpus conservado es abundante y la documentación sobre su recepción más que significativa-, en otras es una determinada «contaminación» extraliteraria —moral, política o ideológica - la que se inmiscuye en nuestro quehacer crítico. Así ha sido con un corpus poético que hubo de escribirse y publicarse en un momento trágico para nuestra historia, con una dictadura militar y reaccionaria detentando el gobierno de la nación durante cuatro décadas y una comunidad literaria dividida entre la diáspora del exilio y las complejas vicisitudes del interior, una comunidad literaria que hubo de enfrentarse así con los fantasmas y las nostalgias de un pasado reciente cuyas heridas no cicatrizaban en ellos como la propaganda oficial del régimen prescribía. 
Así las cosas, y desde entonces, buena parte de las diversas lecturas críticas realizadas a tenor de esta poesía española de posguerra han ido adoleciendo, bien de un recato ideológico más o menos impuesto - durante el propio tiempo de la dictadura-, bien de una declarada e intencionada vocación «moral» — durante el tiempo de transición, consolidación y normalización democráticasque en la mayoría de las ocasiones buscaba «hacer justicia» pero que, en otras, revelaba un afán de revanchismo de menor vuelo crítico. Tales lecturas ideológicas eran en todo caso lícitas, siempre y cuando se declararan como tal.

Lejos, pues, de condenar las implicaciones morales o más mondamente políticas, según los casos, de cada una de las interpretaciones críticas de esta índole que se hayan ido "construyendo» hasta la fecha, nuestro propósito es conocerlas y comprenderlas mejor para asumir, en su dimensión histórica, la recepción de nuestra poesía de posguerra. No se trata sino de perfilar en lo posible los difusos límites entre ciencia e ideología, entre observación y sugestión, entre el afán por alcanzar el conocimiento objetivo y la vocación por la narración de lo subjetivo. En este sentido, fue el filósofo francés Paul Ricoeur quien, por aquellas mismas fechas en que Jauss y Rodríguez-Moñino planteaban sus observaciones más cruciales, formuló con mayor tino las tensas relaciones entre "ciencia» e «ideología». Así, en el conjunto de conferencias pronunciadas en el otoño de 1975 en la Universidad de Chicago y recogidas diez años más tarde en el volumen Lectures on Ideology and Utopia (Nueva York, Columbia University Press, 1986), Ricoeur repasaba toda la tradición crítica de corte marxista, desde el propio Marx a Mannheim, y, al cabo de las interferencias entre ideología, utopía y, en último extremo, la propia «realidad histórica», el profesor galo concluía:

Hablamos sobre ideología, pero nuestro discurso está él mismo atrapado por la ideología. Por mi parte, sostengo que debemos debatirnos con esta paradoja y superarla a fin de poder avanzar. Formular y aceptar esta paradoja es el punto decisivo de todo nuestro estudio y este nos impulsa a buscar una caracterización mejor de la ideología. Debemos preguntarnos si puede continuar manteniéndose la polaridad de ideología y ciencia o si debe ser sustituida por otra perspectiva (Ricoeur, 1989: 191-192). 
Se trata, por lo tanto, de asumir y superar tal paradoja. No son pues estas unas palabras de condena contra la ideologización del discurso crítico en torno a nuestra literatura de posguerra y, por ende, a toda la literatura escrita durante el periodo franquista, pero sí una advertencia y un análisis de ese proceso.

Siendo estas nuestras intenciones, tomaremos, de entre las múltiples lecturas y construcciones críticas realizadas hasta la fecha al hilo de nuestra literatura de posguerra, tres textos que se nos presentan como altamente significativos de su etapa política y corriente hermenéutica a un mismo tiempo, tres textos con una distancia aproximada de tres décadas entre sí que nos llevan desde el propio cronotopo estudiado - el Mediosiglo - al momento en que lo estudiamos - los primeros compases del siglo XXI- Iniciaremos así el recorrido con el que ha sido, probablemente, el texto que ha influido de manera más decisiva en toda la recepción crítica posterior sobre el asunto: el artículo con el que Dámaso Alonso, en 1952, dividía el panorama lírico nacional entre "arraigados» y «desarraigados». A continuación, y dando un salto desde los años de mayor apogeo y consolidación del régimen franquista durante la década de los cincuenta al de su disolución en un sistema parlamentario y democrático en los años setenta, abordaremos una serie de textos críticos con los que un entonces joven José-Carlos Mainer, muy influido por las propuestas de corte marxiano de Lucien Goldmann, trató de ofrecer un nuevo discurso sobre aquella literatura de posguerra para la España democrática que empezaría a dar sus primeros pasos en aquel decenio.Y dando un nuevo salto de tres décadas, trataremos de analizar una de las pocas construcciones críticas recientes que se ha declarado abiertamente inscrita en una de las tendencias hermenéuticas en boga en estos principios del siglo XXI, la teoría de los polisistemas de Even-Zohar. Tal es el caso de Joaquim Espinós en un artículo publicado en el no muy lejano año de 2006 y en el que la descentralización política y "nacional» de nuestra literatura queda reflejada. Se trata de tres lecturas que pueden ser discutidas o discutibles — ahí radica la esencia misma de la crítica literaria - pero de las que no se podrá decir que no supieron encarnar su tiempo histórico y hermenéutico con honestidad y franqueza. 
EN CLAVE ESTILÍSTICA.

EL ARRAIGO Y EL DESARRAIGO

SEGÚN DÁMASO ALONSO

En un año tan significativo como 1950, uno de los poetas y críticos más influyentes del parnaso español de aquellos años, el catedrático madrileño Dámaso Alonso, publicaba en un extenso volumen - que habría de ser su magnum opus como crítico literario- buena parte de sus trabajos como estudioso de la lírica nacional. Bajo el título Poesía española. Ensayo de métodos y límites estilísticos (Madrid, Gredos, 1950), reunía extensos y sesudos trabajos sobre Garcilaso de la Vega, fray Luis de León, san Juan de la Cruz, Luis de Góngora, Lope de Vega y Francisco de Quevedo. Se nos presentaban así, agavillados en torno al "método estilístico», aquellos poetas clásicos que habían sido alzados nuevamente, desde los tiempos del Noventayocho hasta aquel mediar del siglo, como los grandes fetiches poéticos del país. Todos ellos, no por casualidad, habían pasado recientemente por la moda, tan en boga, de los centenarios. De hecho, Dámaso Alonso fue el verdadero configurador de la marca "Generación del 27", allá por 1948, como nómina cerrada de poetas vinculada al centenario gongorino ${ }^{4}$, y por aquellos mismos y convulsos años se sucedieron igualmente los centenarios de fray Luis - nacido en 1527-, Lope - muerto en 1635-, Garcilaso - muerto en 1536-, san Juan de la Cruz —nacido en 1542- y Quevedo — muerto en 1645-.

No obstante, el volumen del madrileño pretendía algo más que ofrecer su personal análisis de aquella poesía clásica que tanto había sido invocada en la «rehumanización» de nuestra lírica a lo largo de los años treinta y cuarenta del siglo xx, consumada la irrupción de las primeras vanguardias en los veinte. Lo que Dámaso Alonso buscaba conseguir con su Poesía española de 1950 era lo mismo a lo que aspiró Miguel de Cervantes en 1613 con sus Novelas ejemplares, esto es ofrecer, al mismo tiempo que un contenido jugoso en el que ponían lo mejor de sí como ensayista y novelista — respectivamente-,

Pese a los no pocos precedentes de este marbete —el excéntrico Giménez Caballero o Victoriano Crémer como ejemplos distantes entre sí-, fue Alonso quien estableció la "nómina» canónica de sus integrantes y su relación con los actos de homenaje al poeta cordobés en Sevilla durante 1927 en el artículo «Una generación poética (1920-1936)», publicado en la revista Finisterre (n. $\left.{ }^{\circ} 35\right)$ en 1948, y recogido cinco años más tarde en Poetas españoles contemporáneos (Alonso, 1965: 155-177). 
una muestra «ejemplar» de saber hacer en el oficio. No en vano, con aquellos trabajos - reeditados abundantemente desde entonces- Dámaso Alonso hacía entrar en España, por la puerta grande y para el gran público, la llamada "crítica estilística»" Era dicha «estilística» una corriente metodológica que venía gestándose, en un ámbito estrictamente lingüístico, desde que el suizo Charles Bally enunciara sus Précis de stylistique en 1905. Fueron, no obstante, los romanistas germánicos Karl Vossler, Helmut Hatzfeld y Leo Spitzer quienes en el periodo de entreguerras aplicaron de manera sistemática el enfoque de la Stilkritik a los estudios literarios ${ }^{6}$. Alonso conoció este ambiente de primera mano como lector extranjero en el Berlín de 1922 y como profesor visitante en Leipzig en 1934. No obstante, los hallazgos de la estilística germana fueron agudamente amalgamados en España junto a otras propuestas bien conocidas por Dámaso Alonso como las del lexicógrafo y romanista suizo Walther von Wartburg o las del propio Ferdinand de Saussure, sin olvidar el magisterio del incombustible y siempre bien informado Ramón Menéndez Pidal. Esta labor de «importación» del método estilístico dispuso en el ámbito hispanohablante de otro gran activo, el filólogo navarro Amado Alonso, vecino de Buenos Aires desde 1927, y se tradujo en toda una "escuela estilística española», que tuvo en Rafael Lapesa y Carlos Bousoño dos de sus mejores cultivadores, al tiempo que en el poeta y crítico cubano Roberto Fernández Retamar y su Idea de la estilística. Sobre la escuela lingüística española (La Habana, Universidad Central de las Villas, 1958) su mejor síntesis ${ }^{7}$.

En cualquier caso, la filiación entre la escuela estilística alemana y la española, ambas tildadas de «idealistas», es evidente. Les une el mismo punto de partida lingüístico-formal como método para desentrañar la desviación personal de cada autor —un concepto especialmente desarrollado por Spitzer - en busca de un veredicto inequívoco sobre lo que sería el «estilo personal» del poeta en cuestión. Dicho de otro modo: se procura mediante un análisis

5 En aquella misma colección, la «Biblioteca Románica Hispánica», dirigida a la sazón por el propio Dámaso, se publicaron monografias de Leo Spitzer, Helmut Hatzfeld, Amado Alonso o Carlos Bousoño, entre otras referencias del idealismo estilístico.

6 Para una buena síntesis de su historia y sus propuestas hermenéuticas, véase Paz Gago (1993).

7 Tan emblemático ensayo ha sido recientemente reeditado en un facsímil al cuidado de Luis Íñigo-Madrigal (Fernández Retamar, 2003). 
lingǘstico pormenorizado de los elementos formales del texto - por ello, preferentemente poético- reconocer no solo los usos y recursos estilísticos del autor, sino su misma sicología, las propias e íntimas intenciones del creador y su texto, una imbricación entre fondo y forma que se juzga no solo deseable y crucial, sino algo mucho más absoluto: infalible. Esta certeza hermenéutica les llevó en ocasiones a una excesiva confianza en la «intuición» personal del crítico, al margen de recepciones intermedias ${ }^{8}$.

Centrándonos en Dámaso Alonso, el autor de Hijos de la ira ya había aplicado en La lengua poética de Góngora (Madrid, Revista de Filología Española, 1935) su fe en una intuición natural del lector capaz más allá de cientificismos - lo que podríamos tildar con toda intención como una «intuición neorromántica»-, así como en la infalible imbricación entre «significante y significado», una relación que, a diferencia de lo expuesto por Saussure para su definición del signo lingüístico, no puede ser considerada como totalmente «arbitraria»:

$\mathrm{Al}$ reducir Saussure el contenido del signo al concepto, desconoce totalmente la esencia del lenguaje: el lenguaje es un inmenso complejo en el que se refleja la complejidad psíquica del hombre. El hombre al hablar no se conduce como una fría y desamorada máquina pensante. Todas las vetas de su vida espiritual —intrincada como una selva virgen— buscan expresión (Alonso, 1971: 25-26).

Esta asociación será, en el caso del quehacer poético, no solo natural sino consciente y motivada: «para nosotros, en poesía, hay siempre una vinculación motivada entre significante y significado" (ibíd.: 31-32). Es desde esta clave idealista y formal, entendida "por "forma exterior" la relación entre significante y significado, en la

8 «El primer conocimiento de la obra poética es, pues, del lector, y consiste en una intuición totalizadora, que, iluminada por la lectura, viene como a reproducir la intuición totalizadora que dio origen a la obra misma, es decir, la de su autor. Este conocimiento intuitivo que adquiere el lector de una obra literaria es inmediato, y tanto más puro cuantos menos elementos extraños se hayan interpuesto entre ambas intuiciones» (Alonso, 1971:38).

9 En el prólogo a su Poesía española de 1950 dirá que «la selección de "método" para el estudio estilístico no se puede hacer por normas de un criterio racional [...] la única manera de entrar al recinto es un afortunado salto, una intuición. Toda intuición es querenciosa, es acto de amor, o que supone el amor» (ibíd.: 11). 
perspectiva desde el primero hacia lo segundo» (ibíd.: 32), desde la que el ensayista madrileño interpreta nuestra mejor poesía áurea. Para hacernos una idea, bastará con citar alguno de los epígrafes del volumen al hilo de Garcilaso, san Juan de la Cruz o Góngora. Así sucede con enunciados como «¿Por qué Garcilaso usa aquí hipérbaton?», «Expresión de serena majestad: ritmo yámbico», «Función estética del adjetivo», «¿Una quiebra de la sintaxis gongorina?» o «Proliferación de elementos metafóricos de segundo grado».

Así las cosas, tan solo dos años más tarde y en la misma «Biblioteca Románica Hispánica» de Gredos, el autor de Oscura noticia aplicará su método —o su "no-método", según él一 a los poetas de su tiempo y generación ${ }^{10}$. Reunía así en Poetas españoles contemporáneos trabajos publicados o inéditos sobre los Machado, Alberti, Salinas, Guillén, Diego, Aleixandre, Panero, Conde o Rosales, entre otros. Y si en 1950 Poesía española se abría con el gran emblema de la «rehumanización» de los años treinta, Garcilaso de la Vega, Poetas españoles contemporáneos hacía lo propio en 1952 con el otro pilar de aquel impulso neorromántico anterior y posterior a la guerra civil, Gustavo Adolfo Bécquer, el otro centenario del malogrado año de $1936^{11}$. Es en este volumen, el mismo en el que como ya se ha dicho fijará la nómina canónica del Veintisiete en su vinculación con el centenario gongorino, donde Dámaso expone su dicotomía, tan repetida - y manipulada - desde entonces, entre la poesía «arraigada» $\mathrm{y}$ «desarraigada» de nuestra posguerra. Conviene, por lo tanto, fijar el instante y el contexto en que dichos marbetes vieron la luz.

Fue en su reseña del celebrado poemario de Leopoldo Panero Escrito a cada instante (Madrid, Ediciones Cultura Hispánica, 1949), con el que el poeta astorgano logró el Premio Nacional de Poesía de aquel año, donde Dámaso Alonso adelantó la hoy tan conocida etiqueta. Exponía así, bajo el escueto título de "Poesía arraigada», en el noveno número de Cuadernos Hispanoamericanos, en mayo de 1949, su lectura de un libro que emparentaba con Unamuno

10 «Yo entiendo - pero el poeta probablemente no lo ha pensado así- "generación" en el sentido más amplio: todos los vivientes, porque esta losa pesa lo mismo sobre jóvenes que viejos» (Alonso, 1965: 351).

11 El capítulo, uno de los más extensos, se titula "Originalidad de Bécquer» (ibíd.: 13-47). 
y Antonio Machado (Alonso, 1949: 692) ${ }^{12}$. Dirige su análisis, mediante una serie de fragmentos seleccionados, hacia la raíz existencial y local - a un tiempo- de aquellos versos. De hecho, al caserón familiar de los Panero en Astorga, Castrillo de las Piedras, nos remiten los versos del poema "El peso del mundo», de donde Dámaso toma el célebre vocablo:

$$
\begin{aligned}
& \text { Vivir hoy siempre, y estar } \\
& \text { arraigado aquí y ahora } \\
& \text { como Castrillo y Nistal... }
\end{aligned}
$$

Tres años después, Dámaso incluiría aquella crucial reseña en Poetas españoles contemporáneos bajo el título de «La poesía arraigada de Leopoldo Panero» (Alonso, 1965:315-337), al tiempo que escribía para dicho volumen lo que será el desarrollo de aquel concepto, apenas sugerido, de «poesía arraigada» (ibíd.: 345-358). Y no solo eso, sino que se definirá, por contraste, una corriente complementaria y refleja: la «poesía desarraigada». Planteada pues, en aquel 1952, la célebre dicotomía entre poesía arraigada y poesía desarraigada, conviene aclarar ya, como punto de partida señalado por el propio Dámaso, la raíz puramente estilística de dichas categorías:

En este libro se ha hablado alguna vez de poesía «arraigada». Nos conviene ampliar ahora ese concepto. El panorama poético español actual nos ofrece unas cuantas imágenes del mundo, muy armónicas o bien centradas, o vinculadas a un ancla, a un fijo amarre: todo lo llamaré poesía arraigada. Es bien curioso que en nuestros tristísimos años hayan venido a coincidir, en España, unas cuantas voces poéticas todas con fe en algo, con una alegría, ya jubilosa, ya melancólica, con una luminosa y reglada creencia en la organización de la realidad contingente. Digo "hayan venido a coincidir», porque esas voces no pueden ser más distintas (ibíd.: 345).

Dichas voces «arraigadas», que «venían a coincidir» sin imperativo político o programático alguno, sino que lo hacían por convergencia y desde los propios mecanismos estilísticos — personales - del

12 Aquella palabra, «arraigada», aparece también, y no por casualidad, en ese mismo número de Cuadernos Hispanoamericanos. Lo hace, vinculada a «un Antonio Machado, un primer Juan Ramón», en la reseña que Luis Felipe Vivanco realiza de otro libro crucial de aquel año y aquel grupo: La casa encendida de Luis Rosales (Vivanco, 1949: 725). 
quehacer poético, serían, según Dámaso, las voces «distintas» de Jorge Guillén —el júbilo ante lo creado-, Leopoldo Panero y José Antonio Muñoz Rojas — ambos en el canto al terruño familiar- y José María Valverde — la fe entregada en Dios- Cuatro poetas de tres promociones, por edad de nacimiento, sucesivas. Y, con ellos, tres ejes temáticos que alguno podría intentar relacionar con los tres pilares de aquel "primer franquismo" de la posguerra: el vitalismo falangista, el localismo tradicionalista y la religiosidad del nacionalcatolicismo, si no fuera, claro está, porque las biografias políticas de Guillén yValverde, pero también de Muñoz Rojas y Panero, se prestan dificilmente a tales torceduras. Los juicios de Dámaso quedaban, pues, muy lejos de la lectura moral, o mejor dicho política — esto es: una poesía arraigada afecta al régimen franquista frente a una poesía desarraigada como oposición al mismo-, que posteriormente, en su recepción histórica, se le ha adherido.

Así sucede también con su proposición del «desarraigo». El siempre hábil Dámaso — que, como hemos visto, perfiló en aquel mismo libro una nómina oficial del Veintisiete en la que oportunamente se incluía y que en el mismo año de 1944 publicó dos poemarios que podrían representar la doble vía del arraigo y el desarraigo de manera portentosa, Oscura noticia e Hijos de la ira respectivamente- se incluye entre los poetas que encarnarían una actitud de desarraigo y desaliento existencial ante las ruinas fisicas y morales surgidas de la segunda guerra mundial:

Para otros, el mundo nos es un caos y una angustia, y la poesía una frenética búsqueda de ordenación y de ancla. Sí, otros estamos muy lejos de toda armonía y toda serenidad. Hemos vuelto los ojos en torno, y nos hemos sentido como una monstruosa, una indescifrable apariencia, rodeada, sitiada por otras apariencias, tan incomprensibles, tan feroces, quizá tan desgraciadas como nosotros mismos (ibíd.: 349).

Incluido el propio crítico, apenas se sugieren dos nombres más, el donostiarra Juan de Leceta y el bilbaíno Blas de Otero ${ }^{13}$, en el

13 «Algún día quisiera estudiar la obra de varios de esos poetas, y señalar coincidencias, los distintos valores y enormes diferencias. La lista sería bastante norteña» (Alonso, 1965: 349). ¿Apuntaría, con lo de «norteña», además de a los vascos Juan de Leceta (seudónimo, como es sabido, de Gabriel Celaya) y Blas de Otero, a la también vasca Ángela Figuera, a los cántabros José Luis Hidalgo y José Hierro o al burgalés Victoriano Crémer, entre otros? 
que se centra Dámaso en lo que resta de aquel célebre capítulo para desarrollar un análisis que, como decimos, es puramente estilístico, y en el que los polos opuestos de «arraigo y desarraigo» son en realidad las caras de una misma moneda: la obsesión por constatar la presencia de Dios, cumplida en los primeros y frustrada en los segundos. Que es estrictamente estilístico, y algo tramposo, el método damasiano lo evidencia una nota al pie del comentario de un soneto del «arraigado» Muñoz Rojas, cuyo uso «gozoso» del encabalgamiento se opone al empleo abrupto de este recurso formal en Blas de Otero:

El paralelismo de los versos primero y tercero se repite luego, fluido, en el de los séptimo y octavo. Nótese cómo los fenómenos de significante solo operan a través del significado (teoría bien clara en mi Poesía española. Ensayo de métodos $y$ límites estilísticos, pero que alguno se ha entestarado en no querer comprender): aquí los encabalgamientos ásperos no sirven más que como imagen de la incontenible exuberancia, y sobre todo, punto de referencia para la fluidez de los versos que vienen luego. Entiéndase las relaciones entre significante y significado en lo que toca a encabalgamiento por comparación con la técnica de Blas de Otero, poeta del que hablamos enseguida (ibíd.: 347).

Nace la tan repetida dicotomía damasiana, por lo tanto, enclavada en el año de 1952, momento de incuestionable consolidación franquista en el interior y de plena hegemonía formalista entre la crítica más avanzada, una hegemonía que tuvo en el ámbito continental europeo su materialización más clara en la estilística hispanogermana frente al New Criticism del ámbito anglosajón, en el que por esos años trabajaban Salinas, Guillén o Cernuda en los Estados Unidos. La dicotomía expuesta, por otra parte, no fue otra que la que él mismo había cultivado al publicar en un mismo año, como ya se dijo, Oscura noticia (Madrid, Adonáis, 1944) y el quizás más trascendente Hijos de la ira (Madrid, Revista de Occidente, 1944). Esta dicotomía, que era, por supuesto, moral — no política—, era, ante todo, formal: el calibrado soneto de Oscura noticia frente al desasosegante polimorfismo de Hijos de la ira. La indisoluble alianza entre «significante y significado», que diría Dámaso. 


\section{EN CLAVE SOCIAL. ENSAYOS DE INTERPRETACIÓN EN EL PRIMER JOSÉ-CARLOS MAINER}

Cuando el moribundo titular de la dictadura franquista agotaba sus últimos días, los ámbitos cultural y académico españoles estaban muy lejos del discurso oficial de un régimen convertido en epígono de sí mismo. Tardofranquismo, transición y democracia fueron sucediéndose y solapándose en un devenir histórico complejo pero de dirección inequívoca. En un momento en el que España se redefinía como ente político y en el que su historia —al menos la de su último siglo- debía ser reinterpretada convenientemente, resulta bastante comprensible la gran acogida que recibieron las teorías críticas de raíz sociológica. En este sentido, interesaron muy especialmente las aportaciones al enfoque marxista de la sociología de la literatura que se debieron a la renovación impulsada, durante los años sesenta, por el crítico franco-rumano Lucien Goldmann, que trató de aplicar el método estructural a sus fines.

Fueron autores como Louis Althusser, Pierre Macherey y, sobre todo, el propio Goldmann quienes cuajaron en un sistema estructural aquel enfoque que todavía hoy entendemos por "marxista» en el ámbito de la teoría literaria. Partían de una fe absoluta en la relación entre la estructura económica y la superestructura ideológica - particularmente en Goldmann - que marcaba el signo de una corriente que trataba de detectar la «visión del mundo» o Weltanschauung del grupo social al que el autor literario en cuestión pertenece y desde el que consciente o inconscientemente - e, incluso, involuntariamente, y aquí está la clave- opera en sus textos (Goldmann, 1985; Goldmann et al. 1971). Este «estructuralismo marxista», como algunos autores lo denominan, tuvo una gran y determinante acogida entre la crítica española durante los últimos años de la dictadura franquista y primeros compases de la democracia.Tuvo así su recepción en una España inmersa en un momento en el que se sentía como imprescindible "construir» un nuevo discurso político y ético a la altura de las nuevas circunstancias ${ }^{14}$. $\mathrm{O}$, dicho de

14 En el ámbito del Siglo de Oro español, el profesor de la Universidad de Granada Juan Carlos Rodríguez publicó por entonces su Teoría e historia de la producción ideológica. Las primeras literaturas burguesas (siglo XVI) (Rodríguez, 1974). Por su parte, el pensamiento de Goldmann tuvo en Juan Ignacio Ferreras y sus Fundamentos de sociología de la literatura (Ferreras, 1980) su principal discípulo. 
otro modo: en un momento en que había que «reescribir» nuestra historia literaria en oposición a la que habían escrito los vencedores de la guerra cuarenta años atrás. Desde estas premisas de salida, el ámbito literario de la posguerra - concepto que en aquellas fechas se extendió y redefinió hasta las mismas puertas de 1975 - se convirtió en uno de sus principales campos de aplicación.

La obra más señera de este fenómeno fue la sintomática Historia social de la literatura española (en lengua castellana) publicada con gran éxito en Castalia en 1978 - y ampliada en 1981- por Carlos Blanco Aguinaga, Iris Milagros Zavala y Julio Rodríguez Puértolas. En su «Explicación previa», los autores del manual afirmaban:

Solo la conciencia lúcida de la función de la ideología puede salvar al productor y al lector de la presunción de inmutabilidad y validez universal de su obra y de sus juicios. Solo desde el pensamiento marxista, un pensamiento que se piensa a sí mismo críticamente, puede empezarse a desmitificar las pretensiones ideológicas de la producción superestructural, cuyas dos peculiaridades principales son: creer en su independencia absoluta y creer, por lo tanto, que no es determinada por la Historia (sino, si acaso y paradójicamente, que ella determina la Historia) (Blanco Aguinaga, 1978a: 27-28).

Estamos por lo tanto en el polo más opuesto a las propuestas estilísticas damasianas. Desde esta "conciencia lúcida» de la ideología marxista, sin embargo, se quiso juzgar contestatariamente todo nuestro canon literario - sin salirse de dicho canon-, reservando una especial atención, en su tercer tomo, al lugar que la literatura escrita bajo la España franquista habría de ocupar ${ }^{15}$. Así, si bien se reconocen matices entre las posiciones puramente falangistas y las «clerical-autoritarias» o la existencia de puentes con el

Para todo este proceso, véase el excepcional capítulo de Antonio Chicharro Chamorro (2004: 195-236).

15 En opinión de Bellón Aguilera, "[m]ás que un manual "marxista”, palpita en toda la obra una impugnación de la lectura que se había hecho del canon literario hasta el momento, como si se prolongara la lucha contra el franquismo, esta vez en forma de lucha contra las apropiaciones ideológicas e institucionales del mismo. No negamos que haya una metodología marxista en la HSLE [...]. Pero también hay un impulso diferente, que proviene del trauma de la guerra civil y del exilio republicano, a través de los hijos, discípulos y descendientes de los exiliados» (2013: 258). 
exterior como la revista Ínsula de José Luis Cano, la Historia social de la literatura española quiso cargar las tintas de lo absoluto sobre toda una década:

En cuanto a la realidad cultural, se rompió oficialmente todo contacto con el liberalismo europeo, siempre en defensa de una ortodoxia ideológicamente uniforme - religiosa y política, inextricablemente unidas-, en busca de las raíces casticistas de la España eterna. [...] La ideología clerical-autoritaria brilla así cegadoramente en la España de los cuarenta, que asiste a espectaculares despliegues de remembranzas histórico-tradicionalistas [...]. Por lo que se refiere a la estricta producción literaria, se hace preciso señalar el abandono de todo contenido crítico, el vuelco hacia formas tradicionales - como el soneto en poesía- y una temática al margen de la Historia, rigurosamente escapista. Por otro lado, si bien no muy abundantes, no faltan tampoco las muestras de literatura triunfalista por parte de los vencedores (Blanco Aguinaga, 1978b: 78-81).

Se traza un desolador panorama - recordemos expresiones absolutas como «todo contacto», «todo contenido crítico» y notas tan determinantes para un ámbito cultural dado como «cegador» o «escapista» ${ }^{16}$ - que apenas se considera matizado por tres únicas obras, presentadas así de manera aislada: la novela La familia de Pascual Duarte de Cela en 1942, el poemario Hijos de la ira de Dámaso Alonso en 1944 y la pieza teatral de Buero Historia de una escalera en 1949 (ibíd.: 81).

De mayor calado y mejor calibrado fueron las aportaciones de José-Carlos Mainer en trabajos como Falange y literatura (Barcelona, Labor, 1971), Literatura y pequeña burguesía en España (1890-1950) (Madrid, Cuadernos para el Diálogo, 1972) o La Edad de Plata (1902-1951). Ensayo de interpretación de un proceso cultural (Barcelona, Asenet, 1975). En el segundo de ellos, un joven pero ya influyente Mainer reunía varios de sus artículos publicados entre 1966 y 1971 en revistas como Ínsula, Cuadernos Hispanoamericanos —en la que naciera el marbete del «arraigo»—, Papeles de Son Armadans y

16 Véanse así las líneas con que se despacha a la Juventud Creadora como «otra derivación literaria de los vencedores, creadora en todo caso de una seudobohemia para andar por casa, es decir, por el Madrid hambreado y ensombrecido» (Blanco Aguinaga, 1978b: 83). 
Letras de Deusto, artículos con títulos tan sugestivos como «Hacia una sociología del 98» o "La revista Escorial en la vida literaria de su tiempo (1941-1950)». El título, pero sobre todo el prólogo de dicho volumen, subrayaban la vocación nuevamente «ejemplar» de aquella compilación de su quehacer crítico. El joven profesor zaragozano explica haberlo hecho movido por una doble «irritación»:

Respecto a la primera irritación puedo decir que la abonan razones de peso: por lo que atañe al ejercicio de la que podríamos llamar crítica erudita, la ha suscitado ese fantasma del compadreo que flota sobre buena parte de ella, cuando no esa psicosis de casta que obliga a valorar por encima de otra la cantidad de citas al pie de página [...] jcuánta estilística resobada!, ¡cuánto lugar común! [...] ¡cuánto desconocimiento de datos de historia, de economía, de simple información sobre lo que ocurre más allá de las fronteras de la nación o de la misma literatura! ¡cuánta admiración sensiblera por la superficie de fenómenos literarios - Unamuno, Lorca, Machado - que piden a gritos explicación y no exégesis escolástica!

Pero, posiblemente, la mayor dosis de irritación la ha concitado ese propio pasado que intento recapitular y el mismo testimonio literario que analizo; es decir, la historia reciente de mi país, y dentro de ella, la de mi clase social. Parodiando a Larra, diría que hacer sociología literaria en España - y a esto se intentan acercar los trabajos que ofrezco- es llorar; casi mejor diría que es escribir la propia autobiografia moral y más un psicoanálisis urgente con el que pretendemos conjurar algunos de los demonios familiares que nos asaltan (Mainer, 1972: 8-9).

Escrito, pues, al tiempo en que, como el propio Mainer subraya, Juan Goytisolo publicaba sus Señas de identidad oVázquez Montalbán su Crónica sentimental de España, el propósito de aquellos trabajos era declarado: reaccionar contra las lecturas cerradas, inmanentes $\mathrm{y}$ «sensibleras» de la estilística, de un lado, y «recapitular» —id est, «reescribir» - aquel pasado social y literario del que se procedía y de cuyo mejor conocimiento debían hallarse mejores conclusiones sobre aquel presente y su futuro. Había que dejar atrás la estilística damasiana como había que dejar atrás el discurso oficial de una dictadura en vías de diluirse en apenas tres años. La sociología de la literatura de corte goldmanniano - y de abolengo marxista— se 
presentaba, en aquel momento, como el remedio natural para ambas «irritaciones».

Desde estas premisas, Mainer construirá una «vida literaria» de posguerra, de 1941 a 1950, dominada por un contado grupo de «autores — representantes perfectos de la alta burguesía que militó en los partidos más creadores de la derecha bajo la República[que] procedían de grupos fraguados en el Madrid de la anteguerra» (ibíd.: 243) y en la que publicaciones abiertas a debates y contenidos de calidad como la analizada Escorial iban irremediablemente dirigidas «a un público cultural e históricamente aterido», ya que «pese a sus pretensiones iniciales - en no pequeña medida, obligadasEscorial cumplió la tarea de reanudar la complicidad de la burguesía y la literatura» (ibíd.: 262). Era así la de Mainer una lectura "de clase» que trataba de organizar mejor el solo en apariencia uniformado ámbito cultural del primer franquismo.

Pasados unos cuantos años, en su Historia, literatura, sociedad, un Mainer ya maduro se recordaba a sí mismo como «un profesor universitario que estudiaba Filología Románica allá por los míticos aledaños de 1968" y que

empezó a trabajar sobre las letras del siglo xx cuando eran terra incognita a la que nunca se arrimaban los programas escolares y sobre las que pesaban interdictos derivados de la reciente guerra civil cuando no prejuicios sobre la oportunidad académica de estudios tan próximos en el tiempo. Que creyó en la fecundidad de una "sociología de la literatura» que había conocido, en tempranas lecturas de Goldmann, pero que hoy huye como de la peste de tal troquelación, por más que siga frecuentando las páginas del autor de Le Dieu caché (Mainer, 1988: 13).

En este sentido, el Mainer de 1988 señala grietas, pero también hallazgos, en las tesis de Goldmann ${ }^{17}$, concluyendo en último extremo que

17 «Puede apreciarse que las tesis de Lucien Goldmann encierran algún punto de escasa precisión [...] pero también dos conclusiones de primera magnitud: la que concierne a la imposibilidad individual de conformar una "conciencia" que impulse a su vez una determinada "visión del mundo" y aquella que se refiere a la aparente falta de homología entre la realidad social y su reflejo artístico y, por descontado, a la ausencia de univocidad en dicho reflejo» (Mainer, 1988: 125). 
son muchos más los caminos que abre la consideración de reciprocidad en el binomio "literatura-sociedad». El error de casi todas las «sociologías de la literatura» ha sido otorgarse a sí mismas la exclusividad en la exploración de tales relaciones, con lo cual sus simplificaciones, sus apriorismos, su olvido de que la literatura es una modalidad muy peculiar de las superestructuras (por usar del término marxista), han revelado con presteza sus insuficiencias (ibíd.: 149-150).

Fue así, ciertamente, como la presencia de unas premisas de salida, de una "comprometida» voluntad de reescribir nuestro discurso historiográfico tras la caída de la dictadura, condicionaron, en último extremo, el libre ejercicio crítico en aras de un «nuevo» dirigismo nada inocente. Se consolidó, con ello, una visión muy negativa de nuestro ámbito literario de los años cuarenta que todavía hoy perdura, incluso, entre amplios sectores especializados. Fue, con todo, una lectura que, a pesar de sus excesos, en no pocas ocasiones supo ser rigurosa.Y fue, ante todo, una lectura que se hizo necesaria en un tiempo en el que el país trataba de superar traumas y heridas abiertas varias décadas atrás. De su correcta asimilación y matización han de nacer los discursos críticos que, ya en este nuevo siglo, habremos de «construir».

\section{EN CLAVE PLURAL. ESPAÑA COMO POLISISTEMA EN JOAQUIM ESPINÓS}

Un cambio de siglo, por meramente simbólico que sea, no es poca cosa. Los primeros compases del siglo XXI son, con todo, vástagos innegables de las tres últimas décadas del xx: lo que se viene denominando, no sin polémicas, la «posmodernidad». En lo que a la hermenéutica literaria se refiere, la quiebra de las certezas del estructuralismo como método infalible - fuera este formalista o marxista, inmanente o sociológico - se tradujo desde finales de los sesenta en una diáspora de propuestas englobadas bajo el marbete común del postestructuralismo. Tal tránsito lo personifica como nadie el filósofo francés Roland Barthes, que pasaba de publicar Critique et verité en 1966 a firmar su sugerente $S / Z$ en 1970 . Esta crisis de la interpretación unívoca encontró sus postulados más radicales en el deconstructivismo del también francés Jacques Derrida. 
Pero más allá de su cierta desviación hacia el nihilismo y el relativismo, de la que ha sido acusado parte del postestructuralismo — particularmente el deconstructivismo-, su cuestionamiento de todo "centro constructivo" provocó discursos críticos alternativos frente a las pretensiones de infalibilidad de dichos centros de interpretación, fueran estos la crítica lingüística inmanente, el poder institucional atacado por Michel Foucault o Italo Calvino, el discurso patriarcal contestado por una crítica feminista de más larga tradición pero de enorme vigencia en las últimas décadas, el relato eurocéntrico combatido por los llamados Postcolonial Studies o la noción canónica de "alta cultura» a la que se oponen los Cultural Studies norteamericanos. Se trata de discursos alternativos que a menudo resultan enriquecedores y complementarios, pero que en otras ocasiones se revelan tan coactivos y dogmáticos como los relatos que pretenden abolir $^{18}$.

En cualquier caso, esta «descentralización» del discurso crítico cristalizó, en su mejor versión, en un desplazamiento de la noción — desterrada - de «estructura» por la de "sistema». Así sucedió en corrientes como la llamada Teoría empírica de la literatura o la Teoría de los polisistemas ${ }^{19}$. Desde esta última corriente, el profesor israelí Itamar Even-Zohar articuló junto a su Culture Research Group una solución que permitía salvar a un tiempo la construcción de sistemas literarios estructurados —Even-Zohar reivindicó sus deudas con el formalismo ruso y el estructuralismo checo- y la

18 «Lo cierto es que, pese a presumir de ser una actividad intelectual plural, tolerante, que participa como ninguna de la apertura hacia el Otro o lo Otro característica del posmodernismo, los Estudios Culturales causan la impresión de ser bastante exclusivistas y censores, pues permiten que se hable abiertamente de unos temas (de las minorías étnicas, culturales, sexuales, etc.) pero rechazan (también abiertamente) otros» (Viñas Piquer, 2007: 571).

19 «La noción clave, en el ámbito de ambas teorías - la empírica y la de los polisistemas- es sin duda la de sistema literario. Esta noción implica una definición de la literatura de carácter funcional. Es decir, la literatura se estructura como un conjunto de elementos interdependientes y cada uno de ellos desempeña una función en el sistema, una función que está determinada por su relación frente a los otros elementos. Lo que interesa entonces es estudiar todos los componentes del sistema y las relaciones que se establecen entre ellos. El texto literario es solo uno de esos componentes y como tal es tratado, de manera que deja de ser considerado el elemento principal, con lo que se pone fin al textocentrismo característico de todas las poéticas textuales dominantes en los años centrales del siglo XX» (ibíd.: 558). 
interpretación plurívoca del ámbito cultural ${ }^{20}$. Juzgamos el modelo polisistémico, en este sentido, como la más acertada y ponderada visualización de las relaciones de tensión y diálogo entre un sistema cultural dominante y los sistemas periféricos de un momento histórico dado. Si bien los primeros artículos de Even-Zohar se remontan a 1970 — en el arranque mismo del postestructuralismo-, fue con la publicación del volumen Polysystems Studies (Tel-Aviv, The Porter Institute, 1990), fundamentalmente, y con la de Paper in Culture Research (Tel-Aviv, Unit of Culture Research, 2010), cuando su noción de "sistema literario" ha quedado definitivamente fija$\mathrm{da}^{21}$. De esta forma, ciertamente, se ha ampliado nuestro foco de atención más allá del discurso hegemónico en cada cronotopo estudiado, y ello no para abolirlo sino para ubicarlo en su lugar exacto. Ganamos así en profundidad y precisión, desde luego. Perdemos a cambio, no obstante, capacidad de generalización. Descubrimos los componentes de un sistema de sistemas y los rasgos diferenciadores que caracterizan y distinguen dichos sistemas. Pero corremos el riesgo, por el contrario, de no advertir las sinergias comunes que puedan definir el polisistema común.

En nuestro ámbito de estudio, esta descentralización se ha aplicado - bajo el paraguas conceptual de los polisistemas o, generalmente, al margen de él- mediante el estudio pormenorizado del panorama poético español de los cuarenta entendiéndolo como una suma de revistas, grupos o nombres bien delimitables - e incluso opuestos o incompatibles - que nos ha llevado a conocer muy bien todas y cada una de las piezas de nuestro puzle, pero que nos ha privado de una comprensión global y coordinada de todo ello. De su montaje final, en suma. Esto ha sido así, de manera mucho más evidente, en el tratamiento del sistema - o polisistema- literario español en el exilio frente al sistema —o polisistema- literario en el interior.

Junto a las delimitaciones geográficas dialogan, además, las lingüísticas. En este sentido, ha sido desde el ámbito de los estudios catalanes desde el que se nos ha ofrecido la panorámica de nuestra

20 En este mismo sentido se han desarrollado tendencias como el New Historicism norteamericano de Stephen Greenblatt — con base en Foucault — o la teoría de campos de Pierre Bourdieu.

21 Para un análisis de la Teoría de los polisistemas, así como de su presencia en la última crítica literaria española, véase Díez Martínez (2014). 
posguerra poética más apegada al modelo polisistémico ${ }^{22}$ En su artículo de 2006 «La poesia hispànica de postguerra com a polisistema”, Joaquim Espinós aplicaba el modelo de Even-Zohar a nuestra poesía de posguerra — periodo que en su caso extiende hasta 1970,

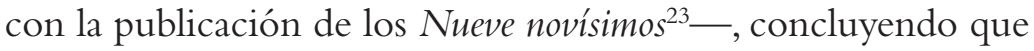

[1]es literatures hispàniques constitueixen un clar exemple de polisistema, segons el model proposat per Itamar EvenZohar. Els sistemes que el componen comparteixen una sèrie de trets comuns a causa de la seua inclusió en un mateix context historicopolític i unes mateixes estructures estatals, però conserven un grau variable d'autonomia basada en llur particular tradició literària (Espinós, 2006: 114).

En este sentido, Espinós traza una panorámica en tres fases: la inmediata posguerra — que alcanzaría hasta 1945 - la primera consolidación del régimen — hasta 1959- y su segunda consolidación — hasta 1970 - Dividida así la posguerra — esto es, el franquismo como tal, excluyendo el llamado tardofranquismo de los setenta-, Espinós señala, «almenys en els primers anys de la postguerra i en bona part de la primera consolidació del règim [...], dos subpolisistemes autònoms: el de la literatura de l'interior i el de la literatura de l'exili» (ibíd.: 104). A esta dualidad de subpolisistemas «autònoms» entre el exilio y el interior — cada vez menos autónomos conforme avanzan los años y el régimen franquista se siente consolidado- se sumarían, claro está, los distintos sistemas idiomáticos, esto es la literatura española —o hispánica - escrita en cada una de las lenguas estatales distintas del castellano. Frente a la hegemonía institucional de este, los casos del catalán, el gallego y el vasco ofrecerían así una línea evolutiva que va, en el interior, de la clandestinidad de los primeros años a la permisividad lingüística de los cincuenta y la relativa

22 Como señala Espinós, «les diverses expressions literàries que conformen la literatura hispànica - la catalana, la castellana, la gallega i la basca - conformen un polisistema de grans possibilitats hermenèutiques insuficientment explorat. Un polisistema cohesionat per un context històric i institucional comú, però diferenciat per l'existència d'unes tradicions nacionals pròpies» (2006: 103).

23 «L'etapa de postguerra finalitza el 1975 amb la transició democràtica, però des d'un punt de vista literari podem considerar que la postguerra finalitza amb la majoria d'edat creativa de la generació nascuda després de la guerra civil, coneguda en l'àmbit castellà com del "sesenta y ocho" i que en el gènere poètic es consagra el $1970 \mathrm{amb}$ la celebèrrima antologia de Josep M. Castellet, Nueve novísimos» (ibíd.: 112). 
normalización de los sesenta. En el exilio, a su vez, se describe un movimiento inverso desde la efervescencia de los primeros años - en contraposición a la represión lingüística del interior- al anquilosamiento y disolución posteriores - merced al regreso a España de muchos de los exiliados o a la asimilación de estos en sus países de acogida-. Descritas las partes, Espinós señala las relaciones de los distintos sistemas en el polisistema común, que tal es el fin último de la propuesta hermenéutica de Even-Zohar. Así, entre otros ejemplos de sinergia, señala la disgregación y falta de coordinación entre los distintos puntos de publicación de la literatura española en el exilio —en todas sus lenguas - contraponiéndolas, sin embargo, a toda una serie de elementos de cohesión y unidad:

Certament, un cop desapareguts els vincles institucionals a què obliga la pertinença a un mateix estat $\mathrm{i}$ amb unes condicions de subsistència ben precàries, els escriptors de les respectives llengües es preocuparen tan sols de crear plataformes d'expressió monolingües — revistes, editorials, certàmens literaris-, amb escassa i poc significativa relació entre sí. Bé es cert que els vincles històrics persistien i que l'experiència de l'exili es manifesta en les quatre literatures hispàniques en una sèrie de constants temàtiques $i$ estilístiques que cohesionen el conjunt. Entre les primeres destacaríem la crítica antifranquista, així com els tòpics de la literatura de l'exili de tots els temps: l'enyorança de la pàtria, el sentiment de desarrelament, el viatge al desconegut o l'atracció per l'exòtic. Pel que fa a la vessant estilística, cal remarcar l'emergència en els casos castellà, català i galleg d'un repertori realista que acabarà per esdevenir canònic al polisistema hispànic entre els anys cinquanta $i$ seixanta, quan la literatura de l'exili ha passat a ocupar un lloc purament testimonial (ibíd.: 108).

Esta aplicación explícita del método de los polisistemas al panorama poético de la posguerra realizada por Espinós en 2006 se inserta, en todo caso, en una tendencia general hacia la reformulación de una literatura española "plurilingüística» —e incluso "plurinacional»— en el seno de un debate que viene de lejos — recordemos el epistolario compartido entre Unamuno y Maragall hace ya un siglo - pero que no ha encontrado el caldo de cultivo adecuado hasta la llegada de la democracia. La construcción plurilingüística de lo que ahora se empieza a denominar «literaturas de España» ha 
desarrollado una importante bibliografía en los últimos veinte años y se ha traducido, asimismo, en la inclusión de temas dedicados a las literaturas en catalán, gallego y vasco en el currículo oficial de educación secundaria en todo el país; o en la implantación de nuevos programas universitarios proyectados desde esta nueva óptica, ofertándose en la actualidad un «Grado en lenguas y literaturas españolas» — con el gallego, vasco y catalán como asignaturas de formación básica - de marcada vocación estatal. Se trata de una senda no hegemónica, pero sí muy presente, que ya fue claramente formulada en volúmenes como Literaturas de España 1975-1998: convergencias y divergencias (Amsterdam-Atlanta, Rodopi, 1998). En él, Germán Gullón, citando a Martín de Riquer, nos habla en «El hispanismo ante la España autonómica» de «una cultura y varias lenguas» y llama a "presentarse en nuestra particularidad, pero con una perspectiva universal» (en Hooft Comajuncosa, 1998: 18, 22). Por ello, como concluye Gullón,

el Estado a partir de la Constitución de 1978 ha pasado de ser uno centralista, el propio de la era de Franco, a ser uno autonómico, y, en consecuencia, la rica pluralidad de las autonomías que lo componen con sus respectivas lenguas deben estar presentes en cualquier enseñanza que se relacione con España. El país, y peco de redundante, solo se puede concebir hoy en su pluralidad, lo cual, a su vez, entraña una concepción del mismo en consonancia con el ritmo de desarrollo social de la comunidad internacional (ibíd.: 17-18).

En todo caso, y ciñéndonos de nuevo a la propuesta concreta de Espinós - también reconociblemente inserta en su tiempo, como la realizada por Alonso en el Mediosiglo y por Mainer en los años de la Transición-, diremos que aplicar los principios de la Teoría de los polisistemas al tradicionalmente fragmentario estudio de la literatura española de la posguerra no ha de ser sinónimo, pese a todo, de la diversificación del problema, sino, muy al contrario, un método que puede resultar muy útil a la hora de coordinar las múltiples facetas, manifestaciones y vertientes de un ámbito literario - esto es, de un polisistema literario - complejo por definición. Estamos ante un marco hermenéutico sugerente para los nuevos retos planteados en el discurso historiográfico de nuestro país en un momento - los primeros años del siglo xxI- en que su carácter «uninacional» parece haber entrado definitivamente en crisis. Se trata de una tercera 
propuesta, en suma, que es nuevamente hija de su tiempo histórico y que se inserta, infaliblemente, entre las tendencias críticas dominantes de cada momento. La recepción histórica de aquellos versos escritos hace ya más de medio siglo suma y sigue. 


\section{BIBLIOGRAFÍA}

Alonso, Dámaso (1949). «Poesía arraigada», Cuadernos Hispanoamericanos, 9, pp. 691-709.

- (1965). Poetas españoles contemporáneos, 3. ${ }^{\text {a }}$ ed. aum., Madrid, Gredos.

- (1971). Poesía española. Ensayo de métodos y límites

estilísticos, 5. ${ }^{a}$ ed., reimp., Madrid, Gredos.

Bellón Aguilera, José Luis (2013). «La Historia social de la literatura española.

Recepción y polémica», Sociología Histórica. Revista de Investigación acerca de la Dimensión Histórica de los Fenómenos Sociales, 2, pp. 239-261.

Blanco Aguinaga, Carlos, Zavala, Iris M. y Rodríguez Puértolas, Julio (1978a).

Historia social de la literatura española (en lengua castellana), tomo I, Madrid, Castalia.

- (1978b). Historia social de la literatura española (en lengua

castellana), tomo III, Madrid, Castalia.

Chicharro Chamorro, Antonio (2004). Para una historia del

pensamiento literario en España, Madrid, CSIC.

Díez Martínez, Jorge (2014). Teorías sistémicas de la literatura. Polisistema, campo, semiótica del texto y sistemas integrados, Granada, Universidad de Granada.

EsPINós, Joaquim (2006). «La poesia hispànica de postguerra com a polisistema», Catalan Review. International Journal of Catalan Culture, 20, pp. 101-116.

FernÁndez Retamar, Roberto (2003). Idea de la estilística. Sobre la escuela lingüística española, ed. Luis Íñigo-Madrigal, Madrid, Biblioteca Nueva.

Ferreras, Juan Ignacio (1980). Fundamentos de sociología de la literatura, Madrid, Cátedra.

Goldmann, Lucien (1985). El hombre y lo absoluto. El Dios oculto,

trad. Juan Ramón Capella, Barcelona, Edicions 62.

— et al. (1971). Sociología de la creación literaria, trad. Hugo

Acevedo, Buenos Aires, Ediciones Nueva Visión.

Hooft Comajuncosa, Andreu van (dir.) (1998). Literaturas de España 1975 -

1998: convergencias y divergencias, Amsterdam-Atlanta, Rodopi.

Jauss, Hans Robert (2000). La historia de la literatura como

provocación, trad. Juan Godó Costa, Barcelona, Península.

MAIner, José-Carlos (1972). Literatura y pequeña-burguesía

en España, Madrid, Cuadernos para el Diálogo.

- (1988). Historia, literatura, sociedad, Madrid, Instituto de España - Espasa Calpe. 
Mayoral, José Antonio (ed.) (1987). Estética de la recepción, Madrid, Arco/Libros.

Paz Gago, José María (1993). La estilística, Madrid, Síntesis.

Ricoeur, Paul (1989). Ideología y utopía, ed. George H.

Taylor, trad. Alberto L. Bixio, Barcelona, Gedisa.

Rodríguez, Juan Carlos (1974). Teoría e historia de la producción ideológica.

Las primeras literaturas burguesas (siglo XVI), Madrid, Akal.

Rodríguez-MoÑIno, Antonio (2012). «Construcción crítica y realidad histórica en la poesía española de los siglos XVI y XVII», en Estudios y ensayos de literatura hispánica de los Siglos de Oro, Cáceres, Genueve Ediciones, pp. 47-81.

ViñAs Piquer, David (2007). Historia de la crítica literaria, 2. ${ }^{a}$ ed., Barcelona, Ariel. Vivanco, Luis Felipe (1949). «La palabra encendida», Cuadernos Hispanoamericanos, 9, pp. 723-733. 